\title{
ENHANCING EFFICIENCY OF SMES IN LATVIA
}

Iveta Linina'Dr. oec., Rosita Zvirgzdina' ${ }^{2}$ Dr. oec.

\begin{abstract}
Efficient management and competitiveness of the company has become a decisive growth factor in ensuring sustainable development of SMEs. In order to identify the factors ensuring competitiveness, the authors have studied the factors characterizing and influencing the company's efficiency. As a result, the authors studied by means of a monographic or descriptive method the theoretical base for management efficiency, analysed the trends of the SME sector in Latvia and analysed the application of the principles of the theory of constraints to ensure the efficiency of Latvian SMEs. This research aims to provide companies an insight into the theoretical and real factors of the theory of constraints. As a result of the study, the authors conclude that by exploring the factors of the theory of constraints, companies can manage this process and maybe use it as one of the tools for ensuring competitiveness.
\end{abstract}

Keywords: efficiency, efficiency enhancement theory, theory of constraints, SME.

JEL code: $M 10$

\section{Introduction}

Globalization trends are one of the most important overall causes of change in the world, and one of the most visible effects of globalization is rapid market growth. In recent years, small and medium-sized enterprises (hereinafter SMEs) have increasingly been affected by global challenges and socio-economic processes directly and indirectly. On the one hand, businesses have open access to the world market, but on the other - the pressure of competition has increased. Therefore, increasing management efficiency has become a decisive growth factor in ensuring the sustainable development and competitiveness of SMEs. Since the beginning of the transformation processes in Central and Eastern European countries more than twenty years ago, the economies of these countries have undergone enormous changes. In order to ensure overall national economic growth and an increase in the welfare of the population, how competitive SMEs are in the world and EU markets is of paramount importance. Taking into account today's dynamic business environment, issues related to sustainability of SMEs have become a priority because efficient management of technology, infrastructure and human capital have significantly improved the prospects of economic growth for both individual companies and national economies. In the long run, in order to ensure the competitiveness and development of SMEs, a cost-effective management system must become the priority of each business, moving towards a low-carbon emission and resource-efficient economy. The long-term existence of any business depends on its ability to rationally use resources and generate profits. Problems in the company are caused by ineffective incorrect actions, incompetence or even failure to act. The activities of SMEs are constantly being explored and analysed. Economic and statistical studies of SMEs, scientific publications and surveys conducted by entrepreneurs help identify key issues affecting the development of small and medium-sized businesses. However, in Latvia, unlike most European and countries worldwide, not much fundamental research exists on the prospects for development of SMEs in a rapidly changing environment. Therefore, comprehensive research on SME performance is needed, using the latest statistical data and scientific publications to get an insight of all SME challenges and to address them. This study will help identify the strategic challenges of introducing a concept for enhancing management efficiency in SMEs, which will ensure an increase in their competitiveness and sustainable development. The purpose of the research is to investigate the factors characterizing and influencing the company's efficiency. The tasks set to achieve the goal are as follows: 
1) to analyse the theoretical basis of the principles of enhancement of management efficiency;

2) to describe the role of SMEs in the EU and Latvia national economy;

3) to determine the prerequisites for the implementation of lean management principles and its level of implementation in Latvia SMEs.

Research limitations: 167 Latvia SME managers in private sector companies were surveyed to determine trends in Latvia and to ascertain the level of understanding of entrepreneurs about the possibilities of enhancing efficiency. Due to the specifics of enhancement of management efficiency and the multifaceted nature of the particular research, the following limitations are set: the problems were studied mainly from the methodological and organizational aspects and the business sector, size, etc. was not taken into account in the survey of the respondents. The research period: $1^{\text {st }}$ May 2017 until $1^{\text {st }}$ August 2017.

The following research methods were used: a monographic or descriptive method and a logicalconstructive method - to compare the theoretical material with the empirical results; the survey of business executives was carried out in order to find out the level of application of lean management principles in Latvia SMEs. The theoretical and methodological basis of the research was based on research, works and publications of foreign researchers and specialists in economics (A.Schumpeter, B.Ronen, D.Ricardo, H.Emerson, P. Drucker, R.Chase, W.Dettmer etc.); theoretical and practical insights on the performance of SMEs, assessment of factors influencing performance and management issues, as well as materials from scientific conferences and seminars.

\section{Efficiency of enterprise operations and its management}

At the beginning of the $19^{\text {th }}$ century, D. Ricardo attempted to develop specific schemes to measure capital efficiency. Within the framework of this theory, Ricardo did not consider efficiency as performance, but as a relationship between performance and definite costs, which is an important economic indicator that helps to evaluate and compare the results of different activities (Ricardo, 1922: 455). At the beginning of the $20^{\text {th }}$ century, the business theorist J. Schumpeter introduced the terms "innovation", "effective competition", "effective monopoly" in economic science and studied the impact of innovation on the company in terms of increasing its efficiency (Schumpeter, 1949: 255). The Italian economist V. Pareto designed a model for studying efficiency. In his research, Pareto concludes that no one can improve one's condition without worsening the position of another. This definition of efficiency is called Pareto optimum or Pareto efficiency (Oxford Economic Papers, 1993: 520 - 522). In 1911, Emerson introduced the terms "efficiency" and "effectiveness" in his work "The twelve principles of efficiency". In this work, the concepts of "efficiency" and "effectiveness" were not distinguished; the author believed that they were of the same importance. In his opinion, efficiency (effectiveness) is the most cost-effective ratio between total costs and economy (Emerson, 1917: 423).

The economist F.Drucker focused on the efficiency of companies in more detail. According to F. Drucker, efficiency means the balancing of all production factors that provides the greatest return with the slightest effort. Profit is the result of a company's efficient operations in terms of marketing, innovation and efficiency. He also developed an efficient management model. This model outlines five principles that must be followed by the company's leader in order to be effective: 1) plan their own time; 2) focus on achievements and the end result; 3 ) develop their own strengths and strengths of their employees; 4) necessity to determine the company's priorities 
and focus on certain larger areas of activity that will achieve the best results; 5) making effective decisions (Drucker, 1954: 404).

It can be seen that the interpretation of the concept of "efficiency" differs greatly; each author has his own approach and understanding. The majority of authors associate this notion with the rational use of resources, but there are other interpretations. Mg.oec I. Kotane, in a study "The concept of business efficiency and its interpretation," looked at opinions of several economists - V. Petit, F. Ken, H. Emerson, V. Pareto, R.H. Kouz, P. Druker, T.C. Kumpen et. al. on the development of business efficiency concepts and measurement concepts in order to systematize the translation of the concept of efficiency and find the synonym of the concept of efficiency in Latvian terminology. The study concluded that there is a contradiction in the explanation of the concept and its interpretation. There is one concept of "efficiency" without distinguishing between the explanations of efficiency and effectiveness, and another that is defined as the use of internal enterprise resources that could be attributed to efficiency. The authors conclude that efficiency is based on three characteristic elements: investment, short-term performance and long-term performance. Economic efficiency is determined by the use of resources with minimum waste, while functional effectiveness is determined by the achievement of higher goals (Kotane, s.a .: 107-111). Another efficacy study was conducted at the University of Debrecen, where explanations of efficiency in various dictionaries are mentioned:

efficiency: achieving the desired result with minimal effort, expense, and waste (Victoria Neufeldt, Andrew N. Sparks, 1995); obtaining specific results with as little investment as possible or maximizing the results with existing resources (John Black, Nigar Hashimzade, Gareth Myles, 2002); technical efficiency as the manufacturer's ability to produce a maximum output of acceptable quality with minimal investment and economic efficiency as an organization's ability to manufacture and distribute its products at minimum prices (John Black, Nigar Hashimzade, Gareth Myles, 2009).

The definition of productivity is also mentioned because, according to the authors, it is a similar concept. Productivity is the result of an organization or economy per unit (John Black, Nigar Hashimzade, Gareth Myles, 2002).

So, economic efficiency is the ability of an enterprise to produce a good quality product or provide a qualitative service using as little labour, raw material or capital resources as possible. In turn, effectiveness is the ability of an enterprise to achieve results that meet the set objectives. Summarizing these definitions, it can be concluded that efficiency is the ability of an enterprise to produce a quality product or to provide a quality service with the least investment possible and achieve the set objectives.

Similar to the interpretation of the concept of efficiency, economists disagree in defining the criteria for efficiency. Moreover, each company has its own specifics of work, which also determines which criteria best reflects the organization's performance. Most often, the company's economic efficiency is assessed by profitability indicators. Therefore, these indicators are the ones that are most often mentioned in business literature. In contrast, authors of the earlier mentioned Debrecen University study consider that a company is successful if it is efficient, competitive and liquid. Efficiency is a relative category and its calculation according to a common formula is not sufficient enough to determine whether a company is efficient or not (Nabradi, Peto, Balogh, 2007: 9-10).

In order to select the criteria to use while assessing a company's economic efficiency, the specific its operations, the cash flow and other factors that make the company different from 
others must be taken into account. These criteria can be used by any company after adapting them to the specifics of the particular company.

The study "Business Efficiency and Ergonomics in Latvian Enterprises" conducted by the University of Latvia (LU) in 2014 found that there are some common signs that show an organization is not efficient: it takes a lot of time to do simple things, does not implement short, simple projects that could provide small but immediate returns, planning is ongoing, but no plan is being implemented, not all resources are used, not all employees want to achieve maximum improvements, low self-motivation of employees, attitude to work responsibilities, illogical path between operations, no flow, difficult decision-making process, differing future visions, customer complaints etc. These features are common to both small, medium and large businesses, regardless of their sphere of operations.

The following methods were used to improve efficiency: Benchmarking; Six Sigma (Six Sigma); Theory of Constraints; Statistical Process of Control; Balanced Scorecard; Total Quality Management; Process management; LEAN Management; Excellence Models.

According to the LU study, only a few companies use some of these methods: $56.8 \%$ use the process management method, $58.6 \%$ - LEAN method and $75.35 \%$ - excellence models (Kalkis, Legzdins, Krumholce, 2014). Such a situation in Latvia business shows that insufficient attention is being paid to efficiency issues or they are not being studied sufficiently. There may be various reasons for this - the lack of interest of entrepreneurs in improving their performance, lack of information, and excessive self-esteem. In terms of lack of information, it should be acknowledged that sufficient attention has not been paid to methods of enhancing efficiency in Latvian literature on economics and the above-mentioned theories are not widely discussed (Behmane, Trofimov, Putn, 2013: 9-12).

One of the theories considered to understand the enhancement of management efficiency is the Theory of Constraints. The Theory of Constraints (TOC) is a philosophy of system management, founded by Eliyah M. Goldratt in the early $80 \mathrm{~s}$. The fundamental thesis of the theory argues that constraints create limits to the development of any system. Goldratt developed this theory as a systematic approach to the continuous improvement process, which makes it possible to enhance the efficiency of a company without additional investments.

Several theories on enhancing business efficiency are focused only on processes and not the system as a whole; there is no mention at all of factors limiting the system. TOC is a theory with recommendations that not only explains things that do not allow systems to realize their potential, but also recommends an action plan to improve the situation. Goldratt's theory is devoted to transformations and enhancements and following its principles, one can answer three main management questions: What needs to be changed? What to change to? How to make changes?

Answers to these questions will affect certain processes, but they are formulated to understand what needs to be addressed in order to improve the system as a whole.

Goldratt illustrates the system as a linked chain - this is the main idea of the TOC. If the system functions as a chain, the weakest phase can be detected and fixed. However, the maximum level of occupancy of all stages does not guarantee the efficiency of the whole system; the system can work efficiently even if only one chain stage works at maximum power. According to Goldratt, the system needs to be assessed only as a whole rather than at each stage (Dettmer, 1997: 443).

There are four types of constraints: 1) resource constraints; 2) market constraints; 3) company policy constraints; 4) Dummy Constraints (Ronen, 2006: 51-61). 
In the recommendations section of the theory, five consecutive steps were developed to help concentrate all efforts on specific activities in order to reorganize the whole system in the shortest timeframe: to identify system constraints; reduce the impact of the system constraints; focus all the attention on the system's constraints; eliminate the constraints; return to the first step, not allowing inertia to become a system constraint.

All these instructions are useful, but appear too abstract to be better understood and applied in practice. Goldratt, in his theory, developed specific methods that help identify and successfully eliminate constraints, as well as criteria for measuring results. TOC is more than just a theory. It is a model that includes definitions, recommendations, methods and tools.

The question is how to assess the impact of changes on a system's performance. Part of the answer is hidden in the requirement of identifying the constraining element and ignoring the nonconstraining elements. In this case, it is possible to achieve maximum system performance with a minimum amount of resources, and determine precisely to what extent the improvement of individual elements affects the entire system as a whole. Goldratt developed a very handy technique for determining the efficiency of certain management decisions for the achievement of the goals of the whole system. Each activity is evaluated by the level of impact on three parameters: productivity in terms of cash flow $(T)$, investment $(I)$ and operating expenses (OE).

Goldratt claims that these parameters are interrelated, which means that changes in one parameter leads to changes in the second parameter or in all. If you increase your cash flow $(T)$ productivity by raising your sales, then it's likely that investment (I) and operating expenses (OE) will also increase. If an enterprise is able to achieve a definite income level with the least investment and expense, then more funds remain in the system (net profit).

In order to assess how these criteria change when making decisions, their initial levels must be evaluated. Ideally, T must be maximum and OE and I minimum. It is theoretically possible, but in practice it should be taken into account that productivity in terms of cash flow is limited by the size of the market for the product or service and it is not possible to achieve without expenses or investments. In order to determine the maximum possible return, it is necessary to estimate how much productivity can be increased, given the size of the market and the demand. It is also necessary to set minimum costs and investments, without which the company cannot exist. Comparing these "ideal" indicators with actual indicators, one can conclude where corrections are needed.

If the idea does not lead to productivity in terms of increasing cash flows, then the idea is likely a waste of time and money.

One might wonder what to pay more attention to - T, I or OE. Generally, most companies in a competitive environment focus on reducing expenses (OE), then reducing investment (I), and only then on the system's capability to increase productivity and generate revenue $(T)$.

TOC tools were developed in accordance with the laws of logics in order to successfully manage the process. These are five types of logical tree, laws, and charts: "current reality tree", "conflict resolution diagram" "thunder cloud", "future reality tree", "transition tree" and transformation plan "criteria for checking logical assumptions ". The criteria are used to design the diagram to make sure the existing assumptions are logical. One can also analyse logical trees with their help and understand the course of logical thinking (Dettmer, 1997: 443). 


\section{The role and significance of SMEs in the national economy}

It is recognized worldwide that SMEs play an important role in economic development. This significance is annually confirmed by the Eurostat statistics - micro enterprises provide the same number of jobs as the large companies together ( $40 \%$ ). In support of SMEs, a Small Business Act was adopted in 2008, which stated that it was necessary to support the needs of small and medium-sized enterprises, "to improve the overall policy approach to entrepreneurship" (EU law, s.a.). Its main objective is to integrate the idea of small first into the process of drafting policy documents, to improve the overall policy approach to entrepreneurship, in particular by promoting the development of small and medium-sized businesses and helping to prevent barriers to its development. In Latvia, SMEs, like elsewhere in Europe, account for a large part of the economy and play an important role in generating gross domestic product and employment (Economics Minister, s.a.). The high proportion of small and medium-sized enterprises in both the European Union (EU) and the economy of Latvia e points to the need to evaluate the results achieved by these companies. Companies, both large and very small, are generally drivers of economic growth. Economic globalization will scatter value chains around the world. The globalization of value chains affects not only big companies. More and more, SMEs are shifting their activities to other places, especially to Asia. Many SMEs are learning new forms of businesses and looking for specific competences around the world. This kind of development is complicated, especially for nonmetropolitan SMEs.

The growth and development of SMEs is an essential prerequisite for Latvia's overall growth and competitiveness in the near future. SME development is a matter of national policy, and Latvia's main task is to increase the proportion of SMEs in the economy of Latvia, gradually moving closer to the EU average (50 SMEs per 1000 inhabitants) (Economics Minister, s.a.). It is precisely SMEs in Latvia, which are the basis of the national economy, are most threatened by various risk factors - both by external and internal environment factors. One of the most important features of effective and long-term activity of SMEs is the lean management of the company, which involves the coordinated functioning of the company's internal process and resources similar to that of a clock mechanism: everything is logical; all the details are needed; they fulfil their functions, which are not duplicated; the owner receives a predictable and positive result in the long term - the exact time. Latvia joined the European Charter for Small Enterprises in 2002, whose main goal is to create friendly support policies for small and medium-sized enterprises.

Interest in managing the problems of SMEs was highlighted in the work of the Bolton Committee established in the United Kingdom (1971), which found that the size of the company was relatively related to the size of the sector in the market and the number of competitors in that particular sector of the economy, and outlined the characteristics of such group of enterprises: 1) relatively small market share; 2) the company has no opportunity to influence the level of market prices; 3 ) decisions related to the management of the company are taken by the owner personally; 4) employees are barely involved in the decision making process; 5) the business is institutionally independent, but the freedom of decision making may be restricted to its existing participants (family business, corporation). Summarizing opinions of theoreticians and practitioners regarding the advantages of the existence of small businesses and the significant differences from large companies, the authors conclude that all enterprises, regardless of their size, should identify the most important value generating processes and resources, evaluate the costs associated with value 
creation and focus on cost management using efficiency indicators. As global competition grows, issues relating to quality management of SMEs are becoming more and more important as the company is a key element of the economic system, and the sustainable development of a country or a region is dependent on its ability to function in the long term. This issue becomes particularly relevant in the context of a comprehensive economic downturn. The high proportion of small and medium-sized enterprises in both the European Union (EU) and Latvia economy points out to the need to evaluate the results achieved by these companies with the aim of finding appropriate tools for measuring and managing performance. Taking into account the modern day dynamic business environment, issues of efficient management of SMEs have become a priority because quality management of technologies, infrastructure and human capital can significantly improve the prospects of economic growth both at the individual company as well as national economy level.

\section{The use of lean management concepts in SMEs in Latvia}

The authors conducted a survey of 167 managers of various companies in SMEs during the period May 2017 - August 2017. The questionnaires were developed based on self-assessment model criteria and were drawn up to identify the use of principles of the lean management concept. The respondents' sample was 167 executives selected on a random basis from databases accessible to the authors. All data obtained from the survey were considered valid for the study. All the identified companies met all the SME criteria.

The questionnaire for SME managers is divided into two parts: ability to identify problems and plan measures for resolving the problems. It is possible to evaluate several elements in each section using the Likert scale on a 10-point system, where 1 is very bad, and 10 is excellent. The authors have presented the results of the survey as a summary of two main parts: problem identification and planning measures for resolving those problems (Table 1).

Evaluation of use of principles of the theory of constraints

\begin{tabular}{|c|c|c|c|c|c|c|c|c|c|}
\hline $\begin{array}{l}\text { Use of principles of the theory of } \\
\text { constraints in enterprises }\end{array}$ & 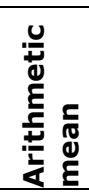 & 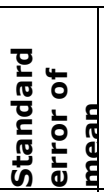 & $\begin{array}{l}\Sigma \\
\frac{\pi}{\delta} \\
\frac{\pi}{\Sigma} \\
\Sigma\end{array}$ & $\begin{array}{l}\stackrel{0}{\mathbf{0}} \\
\mathbf{\Sigma}\end{array}$ & 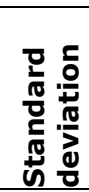 & 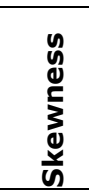 & 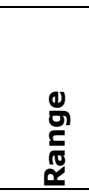 & 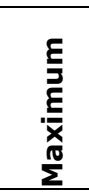 & $\varepsilon$ \\
\hline $\begin{array}{l}\text { Ability to identify system constraints } \\
\text { (What needs to be changed?) }\end{array}$ & 5.78 & 0.76 & 6.00 & 6.00 & 2.28 & 5,19 & 4.38 & 9.00 & 52.00 \\
\hline $\begin{array}{l}\text { Action plan for resolving problems } \\
\text { (What to change to? And how?) }\end{array}$ & 3.22 & 0.70 & 3.00 & 2.00 & 2.11 & 4.44 & 7.27 & 8.00 & 29.00 \\
\hline
\end{tabular}

As it can be seen in the part regarding the company's ability to identify the company's operating system constraints, the average arithmetic mean is above average $(\bar{X}=5.78 ; \mathrm{Me}=6.00$; Mo $=6.00$ ), which could not be considered as positive to ensure management efficiency. The indicator for the second part on action plan for problem solving is very low $(\bar{X}=3.22 ; \mathrm{Me}=3.00$; Mo $=2.00$ ), which indicates very big problems in companies in this area.

Summing up all the results of the research, it can be concluded that the understanding of SME management regarding enhancement of management efficiency in general, including the Theory of Constraint, is low. Researching the principles of this theory, one could also see that the company management is largely unable to identify constraints and even if they are able to identify constraints, they are not able to develop an action plan for eliminating these constraints, which may be the reason for the company's failure to develop and grow. 
The company's management efficiency is based on identifying the company's constraints and developing an action plan for their elimination, which would allow the company to develop and become competitive.

\section{Conclusions and Recommendations}

Summarizing the research results, several conclusions and recommendations can be made.

1) There are several theories and methods on increasing the efficiency of an enterprise's operations. Taking into account the structure of the company and the specifics of the work, it was concluded that the best results will be obtained by the use of criteria and tools of theories of constraints, queues and lean management.

2) Using the Theory of Constraints in the management of a company, the company's operating constraints can be identified and an action plan for their elimination can be developed.

3) The authors recommend that the definition of the EU SMEs be revised to include only small and medium-sized enterprises, which are also most in need of support from the funds, as the definition of small and medium-sized enterprises in the European sense is so broad that it includes practically all companies in the European Union ( $99 \%)$ Consequently, those companies that are really small and need funding are not always able to access it.

4) The overall economic development of Latvia and the increase in welfare of the population depend directly on the extent to which SMEs are sustainable, competitive in the global market. One of the main problems hindering the development of SMEs in Latvia is the business environment. The competitiveness of the SME sector cannot develop without a business-friendly environment. This is largely determined by the degree to which national tax policies are competitive, what kind of capital markets, infrastructure, education systems and state aid effectiveness exist and how well-organized and stable corporate law is.

5) An SME's development strategy for increased profits and economic growth must be linked to the obligation to create enough jobs, to achieve sustainable development and to ensure prosperity. It is important that SMEs develop knowledge-based innovation in the future.

6) Given the large proportion of small and medium-sized enterprises in Latvia from the total number of enterprises, attention should be paid to the effectiveness of self-assessment and the application of various methods of increasing efficiency.

7) An essential condition for ensuring the sustainable development of Latvia SMEs is the ability to analyse achievements and the desire to continuously improve in order to achieve excellence

8) The relatively small number of companies that are able to identify constraints and develop action plans to overcome them can be explained by the lack of understanding of their necessity for the company's development and competitiveness.

9) In order to implement the principles of the Theory of Constraints in practice, Latvia SMEs need to promote accessibility to this theory in the business environment in Latvia.

\section{References}

1. Economics Minister, s.a. Viewed 18.10.2017. http://www.em.gov.lv/em/2nd/?cat=23394

2. Chase, R. B. (1998) "Production and Operations Management ". Irvin, McGraw-Hill Companies, Inc., 950 p.

3. Drucker P. F. (1954) "The practice of management". New York : Harper \& Row, 404 p.

4. Behmane, D., Trofimovs, I., Putnis, D. (2013). „Ārstniecības iestāžu visaptverošas kvalitātes vadības sistēmas metodika". Latvijas veselības ekonomikas asociācija, 9.-12.Ipp.

5. Black, J., Hashimzade, N., Myles, G. (2002). A Dictionary of Economics. Second Edition. Oxford University Press 
6. Black, J., Hashimzade, N., Myles, G. (2009). A Dictionary of Economics. Third Edition. Oxford University Press.

7. Dettmer, H. W. (1997) "Goldratt`s Theory of Constraints. A Systems Approach to Continuous Improvement". ASQ Quality Press Milwaukee, Wisconsin, 443 p.

8. Emerson, H. (1917). "The Twelve Principles of Efficiency" 5th Edition. New York : Engineering Magazine, $423 \mathrm{pp}$.

9. EUR-Lex webpage. Viewed 17.09.2017.

10. http://eur-lex.europa.eu/LexUriServ/LexUriServ.do?uri=COM:2008:0394:FIN:LV:HTML

11. Kalksis, H., Legzdina, L., Krumholce, P. (2014). "Biznesa efektivitāte un ergonomika Latvijas uzņēmumos". LU, Rìga.

12. Kotāne, I. "Komercdarbības efektivitātes jēdziens un tā interpretācija" - Sociālo zinātnuu žurnāls Nr. 1(6), 107.-111. Ipp.

13. Nabradi, A., Peto, K.,, Balogh, V., Szabo, E., Bartha, A., Kovacs, K. (2007). "Efficiency indicators in different dimension". Scientific Papers, Agroinform Publishing House, Budapest.

14. Neufeldt, V., Sparks, A. N. (1995). Webster's New World Dictionary. Pocket Books, 694 p.

15. Oxford Economic Papers. (1993): "Markets and freedom: Achievements and limitations of the market mechanism in promoting individual freedoms", 45 (4), 520-522 pp.

16. Pyzdek, T. (2000). "The Complete Guide to the CQM". Quality Publishing, Inc., 206 p.

17. Ricardo D. (1922). "The Principles of Political Economy and Taxation". London, G. Bell and sons 455 p.

18. Ronen, B. (2006). "Focused Operation Management for Health Service Organizations". U.S. Jossey-Bass 354 p. ; pp. 51-61.

19. Schumpeter, A. (1949). "The theory of economic development: an inquiry into profits, capital, credit, interest, and the business cycle". Cambridge, Mass. : Harvard University Press, 255 p.

20.Smith, A. LL.D. (1902). "The Wealth of Nations". New York, Collier, 457 p.

21.Sztrik, J. (2012). "Basic Queueing Theory". University of Debrecen, 193.p. 